\title{
Comparison of Colonoscopy Surveillance Outcomes Between Young and Older Colorectal Cancer Patients
}

ORIGINAL

ARTICLE

\author{
Sung Bae Kim ${ }^{1,2}$, Hyun Jung Lee ${ }^{1,2}$, Soo Jung Park ${ }^{1,2}$, Sung Pil Hong ${ }^{1,2}$, Jae Hee Cheon ${ }^{1,2}$, Won Ho Kim ${ }^{1,2}$, Tae Il Kim ${ }^{1,2,3}$ \\ ${ }^{1}$ Department of Internal Medicine, ${ }^{2}$ Institute of Gastroenterology, ${ }^{3}$ Cancer Prevention Center, Yonsei University College of Medicine, Seoul, Korea
}

\begin{abstract}
Background: Young-onset colorectal cancer is uncommon, but the incidence is increasing. Despite several guidelines for colonoscopic surveillance following colorectal cancer resection, there is little consistency regarding the timing and age-adjusted strategies of surveillance colonoscopy after surgery of young-onset colorectal cancer. The aim of this study was to compare the outcomes of surveillance colonoscopy between sporadic colorectal cancer patients with young and older age after curative resection.

Methods: We retrospectively reviewed 569 colorectal cancer patients who underwent curative resection between January 2006 and December 2010. The primary outcome was comparison of the development of metachronous advanced neoplasia during surveillance colonoscopy between young and older colorectal cancer patients.

Results: There were 95 patients in the young age group and 474 patients in the older age group. The mean time interval from surgery to the development of metachronous advanced neoplasia was $99.2 \pm 3.7$ months in the young age group and $84.4 \pm 2.5$ months in the old age group $(P=0.03)$. In the multivariate analysis, age $(O R, 3.56 ; P=0.04)$ and family history of colorectal cancer $(O R$, 2.66; $P=0.008$ ) were associated with the development of metachronous advanced neoplasia. None of the young patients without both family history of colorectal cancer and high-risk findings at index colonoscopy showed advanced neoplasia during the follow-up period.
\end{abstract}

Conclusions: Age and family history of colorectal cancer are independent risk factors for the occurrence of advanced neoplasia after curative colorectal cancer resection, suggesting age-adjusted strategies of surveillance colonoscopy.

(J Cancer Prev 2017;22:159-165)

Key Words: Surveillance, Colonoscopy, Colorectal neoplasms, Age of onset

\section{INTRODUCTION}

Colorectal cancer ( $\mathrm{CRC}$ ) is the third most common cancer and a significant cause of cancer-related death. ${ }^{1}$ It is well known that the incidence of CRC increases with age, and most patients are diagnosed at over 50 years of age. ${ }^{1.3}$ However, a recent epidemiologic study showed that over the past few decades, the incidence of CRC has continuously increased in the younger population, aged under 50 years, in contrast to a slight decline in patients older than 50 years. ${ }^{4}$ Despite the rising incidence, the clinicopathological features and prognosis of young-onset CRC remain controversial. ${ }^{5.6}$
Colonoscopic surveillance after curative resection of CRC is important to prevent the development of metachronous CRC in the remnant colon and rectum. ${ }^{7.8}$ Current National Comprehensive Cancer Network (NCCN) and the USA Multi-Society Task Force guidelines suggest colonoscopic surveillance within 1 year after curative resection of $\mathrm{CRC}$ in patients who underwent complete colonoscopy prior to surgery and within 3 to 6 months in those with incomplete preoperative colonoscopy due to obstruction. The subsequent follow-up interval is determined according to the findings of the first follow-up surveillance including the size, number, and pathologic features of adenomas. If the colonoscopy result is negative for any adenomatous or serrated polyps, the

Received August 17, 2017, Accepted August 30, 2017

Correspondence to: Tae Il Kim

Department of Internal Medicine, Yonsei University College of Medicine, 50-1 Yonsei-ro, Seodaemun-gu, Seoul 03722, Korea

Tel: +82-2-2228-1965, Fax: +82-2-393-6884, E-mail: Taeilkim@yuhs.ac, ORCID: Tae Il Kim, http://orcid.org/0000-0003-4807-890X

Copyright (C) 2017 Korean Society of Cancer Prevention

(c) This is an Open Access article distributed under the terms of the Creative Commons Attribution Non-Commercial License (http://creativecommons.org/icenses/by-n//4.0) which permits unrestricted non-commercial use, distribution, and reproduction in any medium, provided the original work is properly cited. 
second surveillance colonoscopy is recommended after 3 years. ${ }^{7,9}$

Current colonoscopic surveillance guidelines after CRC surgery do not consider age, despite the fact that age is a significant factor in the development of adenomatous polyps or advanced neoplasia. ${ }^{10}$ NCCN guidelines mention that more frequent colonoscopies may be indicated in patients who present with colon cancer before 50 years of age. ${ }^{9}$ However, there has been insufficient evidence to support the need for a more intensive colonoscopy strategy in young patients without inherited syndromes, such as Lynch syndrome, familial adenomatous polyposis, and inflammatory bowel disease (IBD). For this reason, heterogeneous follow-up strategies continue to be pursued in colonoscopic surveillance following curative resection.

Therefore, we compared surveillance colonoscopic outcomes between the young and the older CRC patients after curative resection and investigated independent factors associated with the development of metachronous advanced neoplasia to determine whether the young CRC patients may require more surveillance colonoscopies.

\section{MATERIALS AND METHODS}

\section{Patients}

Between January 2006 and December 2010, a total of 795 patients fulfilling the following criteria were initially included in this retrospective review: (1) curative surgical resection due to CRC; (2) available index colonoscopy records; and (3) available records from more than one follow-up surveillance colonoscopy at Severance Hospital in Korea. Patients meeting the following criteria were excluded: (1) stage $4 \mathrm{CRC}$ or palliative resection ( $\mathrm{n}=$ 3); (2) total colectomy or transanal excision $(n=2)$; (3) hereditary CRC ( $n=11)$; (4) IBD ( $n=1)$; (5) history of another malignancy ( $n$ = 27); (6) first follow-up colonoscopy performed more than 2 years after curative resection for CRC $(n=171)$; and ( 7 ) follow-up period of less than 1 year after surgery $(n=3)$. Following the exclusion of 226 patients based on our exclusion criteria, a total of 569 patients were finally reviewed. Surveillance colonoscopy records were collected up to three times after surgery during follow-up periods.

This study was approved by the Institutional Review Board (IRB) of Severance Hospital, Yonsei University in Seoul, Korea (IRB No. 4-2015-1170).

\section{Definition}

Young-onset was defined as age under 50 years at the time of diagnosis. ${ }^{6,9,11}$ Tumor staging was performed according to the
American Joint Commission on Cancer standards contemporaneous to the treatment period. Body mass index (BMI) was categorized as follows: underweight (BMI $<18.5 \mathrm{~kg} / \mathrm{m}^{2}$ ), normal weight (BMI 18.5-22.9 kg/m ${ }^{2}$ ), overweight (BMI 23.0-24.9 kg/m²), and obese (BMI $>25.0 \mathrm{~kg} / \mathrm{m}^{2}$ ). Family history of CRC was defined as prior diagnosis of $\mathrm{CRC}$ in first-degree relatives.

Index colonoscopy was defined as a recent complete colonoscopy with satisfactory preparation prior to surveillance colonoscopy, including postoperative colonoscopy within 6 months in patients who were unable to undergo preoperative complete colonoscopy due to obstruction. ${ }^{12}$ Tumor location was categorized under right colon (cecum, ascending colon), transverse colon, left colon (descending colon, sigmoid colon), or rectum.

Advanced adenoma was defined as an adenoma with (1) villous histology features, (2) a size larger than $10 \mathrm{~mm}$, (3) high-grade dysplasia, and (4) of the serrated sessile type. Advanced neoplasia was defined as adenocarcinoma including intramucosal carcinoma and advanced adenoma. The high-risk patient group was considered to include patients with (1) advanced neoplasia and (2) more than three adenomas. The low-risk patient group was defined as the patients without high-risk findings. Metachronous advanced neoplasia did not include anastomosis site recurrence or locoregional recurrence. ${ }^{10,13}$

\section{Primary and secondary outcomes}

The primary outcome was comparison of the development of metachronous advanced neoplasia during surveillance colonoscopic between young and older patients. The secondary outcome was evaluation of risk factors for postoperative metachronous advanced neoplasia development.

\section{Statistical analysis}

Data are expressed as the median (interquartile range), number, or number (\%), as appropriate. Factors associated with metachronous adenoma and advanced neoplasia were investigated using the Cox regression. Any variables identified as significant $(P<0.05)$ in the univariate analysis were included in the multivariate analysis.

For comparison of the cumulative probability of metachronous lesions, Kaplan-Meier estimator survival analysis was used; the recurrence curves of each group were compared by using a log-rank test. For comparing outcomes, the chi-square test or Fisher's exact test was used for categorical data, and the Student's $t$-test was used for continuous variables. Data analysis was performed using PASW software ver. 18.0 (IBM Co., Armonk, NY, USA). A two-sided $P<0.05$ was considered statistically significant. 


\section{RESULTS}

\section{Baseline characteristics}

Baseline characteristics of the 569 patients are shown in Table 1. The median age at the time of surgery was 43.7 years (28.0-49.0 years) in the young age patients, compared to 63.3 years (50.0-85.0 years) in the older age patients ( $P=0.001)$. In the older age group, a male predominance (65.2\%) was revealed compared to the young age group $(53.7 \% ; P=0.03)$. The proportion of patients with a family history of CRC was $11.6 \%$ in the young age group and $8.9 \%$ in the older age group, with no statistically significant difference. The index colonoscopy findings including existence of synchronous adenoma and advanced neoplasia is more common in old age group significantly ( $P=0.001 ; P=0.03)$. In this context, high-risk patients were more common in the older age group $(P=0.003)$. The young age group showed a high proportion of poor differentiation, mucinous histology (5.3\%), and lymphovascular invasion (30.5\%) in the resected specimens $(P=0.03 ; P=0.02)$. BMI, alcohol history, smoking history, location of tumor, pathologic tumor stage, and preoperative carcinoembryonic antigen titer were not significantly different between the age groups.

\section{Surveillance colonoscopy outcomes}

During the follow-up period, surveillance colonoscopy was performed once in 158 patients (27.8\%), twice in 312 patients

Table 1. Baseline clinical, endoscopic, and pathological characteristics of the patients

\begin{tabular}{|c|c|c|c|}
\hline \multirow{2}{*}{ Variable } & \multicolumn{2}{|c|}{ Age group ${ }^{a}$} & \multirow{2}{*}{$P$-value } \\
\hline & Young age $(\mathrm{n}=95)$ & Older age $(n=474)$ & \\
\hline Age at surgery (yr) & $43.7(28.0-49.0)$ & $63.3(50.0-85.0)$ & 0.001 \\
\hline Sex (male : female) & $51(53.7): 44(46.3)$ & $309(65.2): 165(34.8)$ & 0.03 \\
\hline Family history of colorectal cancer & $11(11.6)$ & $42(8.9)$ & 0.40 \\
\hline Body mass index $\left(\mathrm{kg} / \mathrm{m}^{2}\right)$ & & & 0.19 \\
\hline Below weight $(<18.5)$ & $4(4.2)$ & $9(1.9)$ & \\
\hline Normal (18.5-22.9) & $45(47.4)$ & $185(39.0)$ & \\
\hline Overweight $(23.0-24.9)$ & $22(23.2)$ & $130(27.4)$ & \\
\hline Obese $(>25.0)$ & $24(25.3)$ & $150(31.7)$ & \\
\hline Alcohol & $54(56.8)$ & $235(49.6)$ & 0.20 \\
\hline Smoking & $38(40.0)$ & $184(38.8)$ & 0.83 \\
\hline \multicolumn{4}{|l|}{ Index colonoscopy finding } \\
\hline Adenoma positive patient & $31(32.6)$ & $269(56.8)$ & 0.001 \\
\hline Advanced neoplasia ${ }^{\mathrm{b}}$ positive patient & $19(20.0)$ & $147(31.0)$ & 0.03 \\
\hline Adenoma size $(\mathrm{mm})(\max )$ & $13.0 \pm 13.4$ & $10.3 \pm 7.9$ & 0.09 \\
\hline High-risk patient ${ }^{\mathrm{c}}$ & $20(21.1)$ & $175(36.9)$ & 0.003 \\
\hline Location of tumor & & & 0.37 \\
\hline Right colon (cecum, ascending colon) & $20(21.1)$ & $113(23.8)$ & \\
\hline Transverse colon & $5(5.3)$ & $23(4.9)$ & \\
\hline Left colon (descending colon, sigmoid colon) & $33(34.7)$ & $195(41.1)$ & \\
\hline Rectum & $37(38.9)$ & $142(30.0)$ & \\
\hline AJCC stage & & & 0.08 \\
\hline I & $28(29.5)$ & $154(32.5)$ & \\
\hline II & $28(29.5)$ & $180(38.0)$ & \\
\hline III & $39(41.1)$ & $140(29.5)$ & \\
\hline Differentiation & & & 0.03 \\
\hline Well & $25(26.3)$ & $110(23.2)$ & \\
\hline Moderate & $60(63.2)$ & $346(73.0)$ & \\
\hline Poor & $5(5.3)$ & $10(2.1)$ & \\
\hline Mucinous & $5(5.3)$ & $8(1.7)$ & \\
\hline Lymphovascular invasion & $29(30.5)$ & $94(19.8)$ & 0.02 \\
\hline CEA (ng/mL) & $4.6 \pm 8.4$ & $4.5 \pm 9.3$ & 0.96 \\
\hline
\end{tabular}

Values are presented as median (range), number (\%), or mean \pm SD. The sum of the percentages does not equal $100 \%$ because of rounding. AJCC, American Joint Committee on Cancer; CEA, carcinoembryonic antigen. ${ }^{a}$ Age group defined as young age $(<50$ years) and older age ( $\geq 50$ years). ${ }^{b}$ This was defined as adenoma with (1) villous histology feature, (2) size larger than $10 \mathrm{~mm}$, (3) high-grade dysplasia, (4) serrated sessile type, and (5) adenocarcinoma. 'These were defined as patients with advanced neoplasia or adenoma numbers more than three. 
(54.8\%), and three times in 99 patients (17.4\%). The median time interval from the surgery to the first surveillance colonoscopy was 13.0 months. The mean periods of time from the first colonoscopy examinations to the second and the second to the third were 34.0 months and 28.0 months, respectively. There were no significant differences in the surveillance colonoscopy

Table 2. Comparison of total number and interval of follow-up colonoscopies between the young age and older age patients

\begin{tabular}{|c|c|c|c|}
\hline \multirow[b]{2}{*}{ Variable } & \multicolumn{2}{|c|}{ Age group ${ }^{a}$} & \multirow[b]{2}{*}{$P$-value } \\
\hline & $\begin{array}{l}\text { Young age } \\
(\mathrm{n}=95)\end{array}$ & $\begin{array}{l}\text { Older age } \\
(\mathrm{n}=474)\end{array}$ & \\
\hline \multicolumn{3}{|c|}{ No. of follow-up colonoscopy } & 0.18 \\
\hline 1 & $21(22.1)$ & $137(28.9)$ & \\
\hline 2 & $52(54.7)$ & $260(54.9)$ & \\
\hline 3 & $22(23.2)$ & $77(16.2)$ & \\
\hline \multicolumn{4}{|c|}{ Interval to follow-up colonoscopy } \\
\hline First (mo) & $14.0(12.0-15.0)$ & $13.0(12.0-16.0)$ & 0.70 \\
\hline Second (mo) & $35.0(29.0-37.0)$ & $34.0(26.0-37.0)$ & 0.22 \\
\hline Third (mo) & $26.5(15.7-35.8)$ & $29.0(19.0-37.0)$ & 0.73 \\
\hline
\end{tabular}

Values are presented as number (\%) or median (interquartile range). ${ }^{\mathrm{a}}$ Age group defined as young age $(<50$ years $)$ and older age $(\geq$ 50 years) numbers and intervals between the young and older age groups (Table 2).

During follow-up surveillance colonoscopy, the metachronous adenoma positive rate was $16.8 \%$ in the young age group and $44.1 \%$ in the older age group $(P=0.001)$. The proportion of high-risk patients and number of advanced neoplasia were also higher in the older age group ( $P=0.007$ and 0.02). However, there were no significant differences in the positive rate of metachronous advanced neoplasia between the age groups $(P=0.09)$ (Table 3).

\section{Factors associated with metachronous advanced neoplasia}

Cancer-related factors; patient-related factors including age, sex, BMI, alcohol history, smoking history, and family history of CRC; and index colonoscopy results, such as the existence of synchronous adenoma or advanced neoplasia, size and number of adenomas, and high-risk findings were analyzed to determine independent factors associated with the development of metachronous advanced neoplasia. Among the factors, age $(P=0.03)$, family history of CRC $(P=0.01)$, and high-risk findings on index colonoscopy $(P=0.03)$ were found to be associated with the

Table 3. Comparison of the adenoma incidence rate between the young age and older age patients

\begin{tabular}{|c|c|c|c|}
\hline \multirow{2}{*}{ Variable } & \multicolumn{2}{|c|}{ Age group ${ }^{a}$} & \multirow{2}{*}{$P$-value } \\
\hline & Young age $(n=95)$ & Older age $(n=474)$ & \\
\hline \multicolumn{4}{|l|}{ First surveillance colonoscopy $(95: 474)^{b}$} \\
\hline Adenoma positive patient & $8(8.4)$ & $137(28.9)$ & 0.001 \\
\hline Advanced neoplasia ${ }^{c}$ positive patient & $1(1.1)$ & $16(3.4)$ & 0.33 \\
\hline Polyp size $(\max )(\mathrm{mm})$ & $5.0 \pm 2.2$ & $5.9 \pm 3.2$ & 0.44 \\
\hline High-risk $^{\mathrm{d}}$ patient & $1(1.1)$ & $35(7.4)$ & 0.02 \\
\hline \multicolumn{4}{|l|}{ Second surveillance colonoscopy $(74: 337)^{\mathrm{b}}$} \\
\hline Adenoma positive patient & $9(12.2)$ & $107(31.9)$ & 0.001 \\
\hline Advanced neoplasic ${ }^{c}$ positive patient & $1(1.4)$ & $17(5.1)$ & 0.22 \\
\hline Polyp size $(\max )(\mathrm{mm})$ & $4.1 \pm 2.5$ & $5.8 \pm 5.0$ & 0.32 \\
\hline High-risk $^{\mathrm{d}}$ patient & $2(2.7)$ & $26(7.7)$ & 0.13 \\
\hline \multicolumn{4}{|l|}{ Third surveillance colonoscopy $(22: 77)^{\mathrm{b}}$} \\
\hline Adenoma positive patient & $4(18.2)$ & $37(48.1)$ & 0.01 \\
\hline Advanced neoplasia ${ }^{c}$ positive patient & $1(4.5)$ & $6(7.8)$ & 0.69 \\
\hline Polyp size $(\max )(\mathrm{mm})$ & $10.8 \pm 12.9$ & $5.7 \pm 3.0$ & 0.49 \\
\hline High-risk $^{\mathrm{d}}$ patient & $1(4.5)$ & $12(15.6)$ & 0.29 \\
\hline \multicolumn{4}{|l|}{ Total surveillance colonoscopy $(95: 474)^{b}$} \\
\hline Adenoma positive patient & $16(16.8)$ & $209(44.1)$ & 0.001 \\
\hline Advanced neoplasia ${ }^{c}$ positive patient & $3(3.2)$ & $39(8.2)$ & 0.09 \\
\hline No. of advanced neoplasia ${ }^{c}$ & $0.03 \pm 0.18$ & $0.09 \pm 0.30$ & 0.02 \\
\hline High-risk $^{\mathrm{d}}$ patient & $4(4.2)$ & $68(14.3)$ & 0.007 \\
\hline
\end{tabular}

Values are presented as number (\%) or mean \pm SD. ${ }^{a}$ Age group defined as young age $\left(<50\right.$ years) and older age ( $\geq 50$ years). ${ }^{b}$ Subtotal of young age group : older age group. 'This was defined as adenoma with (1) villous histology features, (2) size larger than $10 \mathrm{~mm}$, (3) high-grade dysplasia, (4) serrated sessile type, and (5) adenocarcinoma. ${ }^{\mathrm{d}}$ These were defined as patients with advanced neoplasia or adenoma numbers more than three. 
development of metachronous advanced neoplasia in univariate analysis. The mean time interval from surgery to the development of metachronous advanced neoplasia was $99.2 \pm 3.7$ months in the young age group and $84.4 \pm 2.5$ months in the old age group. Figure 1 shows the rate of development of metachronous advanced neoplasia between the young and older age groups with Kaplan-Meier survival analysis. Subsequently, multivariate Cox regression analysis, including age group, family history of $\mathrm{CRC}$, and high-risk group, revealed older age $(P=0.04$; OR, 3.56; $95 \% \mathrm{CI}, 1.08-11.74)$ and family history of CRC ( $P=0.008$; OR, 2.66; $95 \% \mathrm{CI}, 1.29-5.48)$ as the independent risk factors associated with metachronous advanced neoplasia (Table 4).

\section{Outcomes according to risk factors}

To identify young patients with a lower risk of metachronous advanced neoplasia in the surveillance colonoscopy, patients were divided into those with either a family history of CRC within first-degree relatives or high-risk index colonoscopic findings and those meeting neither of these two criteria. We identified 89 patients (15.6\%) in the former group and 480 patients $(84.4 \%)$ in the latter group. The mean time interval from surgery to the development of metachronous advanced neoplasia in each of the groups was $71.4 \pm 4.3$ months and $94.5 \pm 3.4$ months, respectively $(P=0.001)$. With further classification according to the age at diagnosis, 82 patients (86.3\%) were categorized as young patients without a family history of $\mathrm{CRC}$ or high-risk features in the index colonoscopy. None of these patients had developed metachronous advanced neoplasia within 161 colonoscopic examinations during follow-up over a mean time period of $44.5 \pm$ 21.5 months.

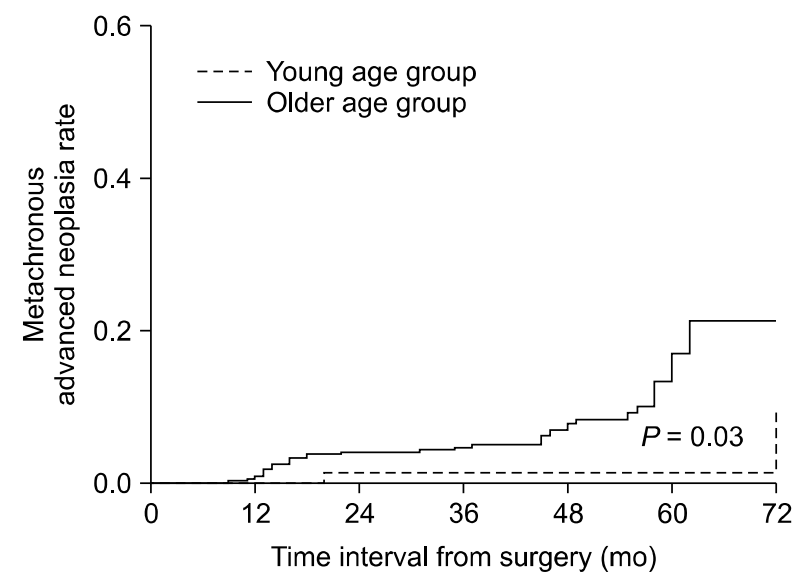

Figure 1. Cumulative probability of metachronous advanced neoplasia during follow-up surveillance colonoscopy. Comparisons of metachronous advanced neoplasia between patients aged under 50 years $(n=95)$ and over 50 years $(n=474)$.

\section{DISCUSSION}

The number of cases of young-onset CRC has been steadily increasing worldwide. Several studies have suggested that these patients may be characterized by more advanced stage disease and a higher incidence of poorly differentiated pathology, as well as a high proportion of hereditary CRC and IBD, compared to older CRC patients. ${ }^{5,11,14}$ The definition of young-onset CRC is still the subject of debate, and the cutoff age varies, ranging from 30 to 50 years. In this study, we used 50 years as the cutoff age because most guidelines recommend screening colonoscopy in average-risk patients at the age of 50 years, and NCCN guidelines also mention that more frequent colonoscopy may be indicated in patients who present with CRC before that age.,11

It is well known that one of the primary benefits of surveillance colonoscopy after curative resection for CRC is the detection of metachronous advanced neoplasia. ${ }^{15}$ Indeed, patients with hereditary CRC or IBD require a more frequent and intensive surveillance strategy, but there is a lack of evidence regarding the timing of the surveillance colonoscopy and whether more frequent colonoscopic surveillance is needed in young-onset CRC patients without risk factors such as hereditary CRC or IBD after curative resection in real life. ${ }^{16-18}$ To solve this

Table 4. Univariate and multivariate analysis for the factors associated with metachronous advanced neoplasia

\begin{tabular}{|c|c|c|c|}
\hline \multirow{2}{*}{ Variable } & \multirow{2}{*}{$\frac{\text { Univariate }}{P \text {-value }}$} & \multicolumn{2}{|c|}{ Multivariate } \\
\hline & & $P$-value & OR $(95 \%$ CI $)$ \\
\hline \multicolumn{4}{|l|}{ Patient factor } \\
\hline $\begin{array}{l}\text { Age group }{ }^{a} \text { (young vs. } \\
\text { older age) }\end{array}$ & 0.03 & 0.04 & $3.56(1.08-11.74)$ \\
\hline Family history & 0.01 & 0.008 & $2.66(1.29-5.48)$ \\
\hline Sex & 0.29 & & \\
\hline Body mass index & 0.11 & & \\
\hline Alcohol & 0.44 & & \\
\hline Smoking & 0.42 & & \\
\hline \multicolumn{4}{|l|}{ Cancer factor } \\
\hline Location & 0.06 & & \\
\hline Stage & 0.50 & & \\
\hline Differentiation & 0.65 & & \\
\hline Lymphovascular invasion & 0.06 & & \\
\hline Preoperative CEA & 0.92 & & \\
\hline \multicolumn{4}{|l|}{ Polyp factor } \\
\hline Adenoma & 0.07 & & \\
\hline Advanced neoplasia & 0.05 & & \\
\hline Size (max) & 0.24 & & \\
\hline Number & 0.21 & & \\
\hline High-risk group & 0.03 & 0.09 & $1.71 \quad(0.91-3.19)$ \\
\hline
\end{tabular}

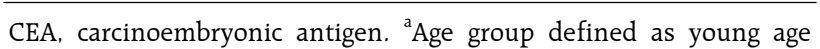
$(<50$ years) and older age ( $\geq 50$ years). 
problem, we focused on comparison of the development of metachronous advanced neoplasia during surveillance colonoscopy between young and older CRC patients without hereditary CRC or IBD.

The percentage of young-onset patients in our study population was $16.7 \%$, and this value is similar to that of a previous study conducted in Asia. ${ }^{14}$ Some reports have suggested that young-onset and right-sided colon cancer is more common in males, but our study population showed a significant male predominance in older patients, with no difference in tumor location. Higher proportions of poor differentiation or mucinous pathology and lymphovascular invasion in the young patients were also consistent with the findings of previous studies. ${ }^{19.20}$ As mentioned above, NCCN guideline suggests more frequent surveillance colonoscopy in young age patients. ${ }^{9}$ However, the timing and number of colonoscopic examinations did not show any differences between the age groups. This result suggested that there is a distinction between guideline and clinical practice.

In the first surveillance colonoscopy, the positive rates of adenoma, advanced neoplasia, and metachronous cancer were $25.5 \%, 3.0 \%$, and $0 \%$. These findings are similar to the previous study results in which $3.2 \%$ of patients developed advanced adenoma and none had newly developed cancer 1 year after undergoing CRC resection. ${ }^{21.22}$ Overall surveillance colonoscopy results comparing age groups revealed that the positive rates of metachronous adenoma, advanced adenoma, and high-risk colonoscopic findings were significantly higher in the older age group. Our results were consistent with the suggestion in the previous studies that older age is a common risk factor for the development of metachronous advanced adenoma in surveillance colonoscopy after CRC resection. ${ }^{10,21,23,24}$

The identification of high-risk patients who require intensive surveillance colonoscopy is a critical issue, and several studies have suggested various risk factors such as aging, synchronous advanced neoplasia, male sex, tumor location, and history of diabetes. ${ }^{21,24}$ In the present study, older age, first-degree family history of CRC, and high-risk colonoscopic findings at index colonoscopy were associated with the development of metachronous advanced neoplasia in univariate analysis. Young patients were definitely at lower risk compared to older patients according to the univariate and multivariate analysis. We also divided patients according to two significant factors in the univariate analysis to more selectively define patients at low risk for the development of metachronous advanced neoplasia. Patients without both family history of CRC and high-risk index colonoscopy findings showed a significantly lower risk for the development of metachronous advanced neoplasia. Moreover, none of the young patients in our study without these two risk factors developed metachronous advanced neoplasia. In our experience, young patients had a low probability of developing metachronous advanced neoplasia, especially those with no family history of CRC and low-risk index colonoscopy findings. As a result, the benefits of an intensive surveillance colonoscopy strategy in this patient group have a relatively low impact on the detection and prevention of metachronous advanced neoplasia.

As a limitation of our study, the timing of surveillance colonoscopy was not equal in all patients, because of the inherent retrospective design of the study. However, we restricted the inclusion criteria to patients with the first surveillance colonoscopy within 2 years after surgery. In addition, in both age groups, the number and intervals of follow-up colonoscopies did not differ significantly.

In conclusion, the present study showed that age is independent factor for the development of metachronous advanced neoplasia after surgery compared to older onset patients. In particular, young patients without a family history of CRC and high-risk index colonoscopy findings have an extremely low rate of metachronous advanced neoplasia. Therefore, colonoscopy surveillance strategy should be adjusted with independent risk factors, including age and family history of CRC.

\section{CONFLICTS OF INTEREST}

No potential conflicts of interest were disclosed.

\section{REFERENCES}

1. Jung KW, Won YJ, Kong HJ, Oh CM, Cho H, Lee DH, et al. Cancer statistics in Korea: incidence, mortality, survival, and prevalence in 2012. Cancer Res Treat 2015;47:127-41.

2. Siegel R, Ma J, Zou Z, Jemal A. Cancer statistics, 2014. CA Cancer J Clin 2014;64:9-29.

3. Sung JJ, Lau JY, Young GP, Sano Y, Chiu HM, Byeon JS, et al. Asia Pacific consensus recommendations for colorectal cancer screening. Gut 2008;57:1166-76.

4. Austin H, Henley SJ, King J, Richardson LC, Eheman C. Changes in colorectal cancer incidence rates in young and older adults in the United States: what does it tell us about screening. Cancer Causes Control 2014;25:191-201.

5. Damodaran D, Seshadri RA. Clinicopathological attributes and outcomes of treatment in young-onset rectal cancer. Int J Colorectal Dis 2016;31:757-9.

6. You YN, Dozois EJ, Boardman LA, Aakre J, Huebner M, Larson DW. Young-onset rectal cancer: presentation, pattern of care and long-term oncologic outcomes compared to a matched older-onset cohort. Ann Surg Oncol 2011;18:2469-76. 
7. Kahi CJ, Boland CR, Dominitz JA, Giardiello FM, Johnson DA, Kaltenbach T, et al. Colonoscopy surveillance after colorectal cancer resection: recommendations of the US Multi-Society Task Force on Colorectal Cancer. Gastroenterology 2016;150:758-768.e11.

8. Meyerhardt JA, Mangu PB, Flynn PJ, Korde L, Loprinzi CL, Minsky BD, et al. Follow-up care, surveillance protocol, and secondary prevention measures for survivors of colorectal cancer: American Society of Clinical Oncology clinical practice guideline endorsement. J Clin Oncol 2013:31:4465-70.

9. Benson AB 3rd, Venook AP, Bekaii-Saab T, Chan E, Chen YJ, Cooper HS, et al. Colon cancer, version 3.2014. J Natl Compr Canc Netw 2014;12:1028-59.

10. Schroy PC 3rd, Wong JB, O'Brien MJ, Chen CA, Griffith JL. A risk prediction index for advanced colorectal neoplasia at screening colonoscopy. Am J Gastroenterol 2015;110:1062-71.

11. Kneuertz PJ, Chang GJ, Hu CY, Rodriguez-Bigas MA, Eng C, Vilar E, et al. Overtreatment of young adults with colon cancer: more intense treatments with unmatched survival gains. JAMA Surg 2015;150:402-9.

12. Jang HW, Park SJ, Hong SP, Cheon JH, Kim WH, Kim TI. Risk factors for recurrent high-risk polyps after the removal of high-risk polyps at initial colonoscopy. Yonsei Med J 2015:56:1559-65.

13. O'Brien MJ, Winawer SJ, Zauber AG, Gottlieb LS, Sternberg SS, Diaz B, et al. The National Polyp Study. Patient and polyp characteristics associated with high-grade dysplasia in colorectal adenomas. Gastroenterology 1990;98:371-9.

14. Yeo SA, Chew MH, Koh PK, Tang CL. Young colorectal carcinoma patients do not have a poorer prognosis: a comparative review of 2,426 cases. Tech Coloproctol 2013;17:653-61

15. Rex DK, Kahi CJ, Levin B, Smith RA, Bond JH, Brooks D, et al. Guidelines for colonoscopy surveillance after cancer resection: a consensus update by the American Cancer Society and the US Multi-Society Task Force on Colorectal Cancer. Gastroenterology
2006:130:1865-71.

16. Rubenstein JH, Enns R, Heidelbaugh J, Barkun A; Clinical Guidelines Committee. American Gastroenterological Association institute guideline on the diagnosis and management of lynch syndrome. Gastroenterology 2015;149:777-82; quiz e16-7.

17. Annese V, Daperno M, Rutter MD, Amiot A, Bossuyt P, East J, et al. European evidence based consensus for endoscopy in inflammatory bowel disease. J Crohns Colitis 2013;7:982-1018.

18. Lieberman DA, Rex DK, Winawer SJ, Giardiello FM, Johnson DA, Levin TR. Guidelines for colonoscopy surveillance after screening and polypectomy: a consensus update by the US Multi-Society Task Force on Colorectal Cancer. Gastroenterology 2012;143:844-57.

19. Mitry E, Benhamiche AM, Jouve JL, Clinard F, Finn-Faivre C, Faivre J. Colorectal adenocarcinoma in patients under 45 years of age: comparison with older patients in a well-defined French population. Dis Colon Rectum 2001;44:380-7.

20. Han-Shiang C. Curative resection of colorectal adenocarcinoma: multivariate analysis of 5-year follow-up. World J Surg 1999:23: 1301-6.

21. Choe EK, Park KJ, Chung SJ, Moon SH, Ryoo SB, Oh HK. Colonoscopic surveillance after colorectal cancer resection: who needs more intensive follow-up? Digestion 2015;91:142-9.

22. Cone MM, Beck DE, Hicks TE, Rea JD, Whitlow CB, Vargas HD, et al. Timing of colonoscopy after resection for colorectal cancer: are we looking too soon? Dis Colon Rectum 2013:56:1233-6.

23. Good NM, Macrae FA, Young GP, O'Dywer J, Slattery M, Venables $\mathrm{W}$, et al. Ideal colonoscopic surveillance intervals to reduce incidence of advanced adenoma and colorectal cancer. J Gastroenterol Hepatol 2015;30:1147-54.

24. Lee SY, Kim BC, Han KS, Hong CW, Sohn DK, Park SC, et al. Incidence and risk factors of metachronous colorectal neoplasm after curative resection of colorectal cancer in Korean patients. J Dig Dis 2014;15:367-76. 